\title{
COMENTARIOS DE SENTENCIAS CONSTITUCIONALES DE LA ADMINISTRACION AUTONOMICA
}

\author{
por
}

\section{Angel Díez Roncal}

\section{EL DERECHO DE REPRESENTACION COLECTIVA DE LOS FUNCIONARIOS PUBLICOS}

(Comentario a la STC 165/1986, de 18 de diciembre, sobre personal de la Diputación Regional de Cantabria)

La reciente sentencia del Tribunal Constitucional, cuyo contenido doctrinal expondremos a continuación, intentando una visión sistematizada del mismo, se produce sobre la materia de Función Pública en el capítulo de los derechos funcionariales que pudiéramos, convencionalmente, calificar de derechos sindicales. La oportunidad de su estudio se subraya especialmente al producirse la publicación de esta sentencia cuando acaba de iniciar su peregrinaje parlamentario el Proyecto de Ley de Organos de representación, determinación de las condiciones de trabajo y participación del personal al servicio de las Administraciones Públicas, enviado por el Gobierno al Congreso de los Diputados en el mes de diciembre.

Por otra parte, constituye un fallo constitucional en esta materia de Función Pública que viene a engrosar la no muy amplia, y quizá no siempre acertada, doctrina del más Alto Tribunal del Estado en tal materia; doctrina que cerrará su primer ciclo cuando el Tribunal se pronuncie, por fin, en los recursos que penden ante él sobre la Ley de Medidas 30/1984 y sobre la Ley de Incompatibili- 
dades 53/1984, los dos pilares de la reforma socialista de la Función Pública.

\section{EL SUPUESTO DE HECHO}

El conflicto de competencia se plantea, a instancia del Gobierno de la Nación, con ocasión del Decreto 37/1983, modificado por el 50/1983, ambos de la Comunidad Autónoma de Cantabria, que regula el ejercicio del derecho de representación colectiva del personal funcionario y contratado administrativo de la Diputación Regional de Cantabria.

La justificación para la promulgación de este Decreto se articula por el Consejo de la Comunidad diciendo: a) que es necesario homogeneizar la situación de los funcionarios públicos con la de los trabajadores en régimen laboral; b) que falta la regulación estatal del derecho de sindicación de los funcionarios, pues no se ha desarrollado el Real Decreto 1522/1977, que contiene normas sobre el ejercicio por los funcionarios de aquel derecho de sindicación.

El contenido del Decreto que se promulga, «con carácter de provisionalidad», por el Consejo de Gobierno de la Comunidad Autónoma se limita a regular el ejercicio del derecho de representación colectiva de los funcionarios a través de un órgano -el Comité de Personal-, determinándose el régimen de su composición, elección, duración del mandato, garantías y facultades de sus miembros, capacidad, competencias y procedimiento laboral. No se desarrolla, según resalta la sentencia, el derecho de asociación sindical en su conjunto, pero sí un «aspecto esencial del mismo»; nos encontramos, pues, ante una regulación de carácter organizativo.

Las razones por las que el Gobierno de la Nación requiere de incompetencia al Consejo de Gobierno de la Comunidad Autónoma de Cantabria, primero, y formula, después, el planteamiento del conflicto de competencia, encuentran su apoyo fundamental en los artículos 28,$1 ; 53,1 ; 81,1 ; 103,3 ; 149,1,1$, y 149, 1, 18, de la Constitución (cuya sola cita es expresiva de la teoría jurídica que sostiene la demanda gubernamental) y, además, en el entendimiento de que, con arreglo a la doctrina de los pronunciamientos del propio Tribunal Constitucional sobre la materia, que es al legislador estatal a quien compete regular el ejercicio del derecho de sindicación de los funcionarios públicos.

Ya hemos recogido en la reseña precedente de la sentencia que 
comentamos que el fallo de la misma resultó adverso a las pretensiones del Gobierno de la Nación, al entender el Tribunal que el Decreto cuestionado no invade las competencias estatales en la materia. Lo que ahora nos interesa es estudiar el itinerario argumental recorrido por la sentencia para llegar a esa conclusión que, en principio, nos parece acertada.

\section{SINDICACIÓN Y REPRESENTACIÓN COLECTIVA}

La sentencia (3) comienza por aclarar que aunque las partes parecen plantear la discusión sobre la distinción entre el ámbito sindical y la representación colectiva, en definitiva, lo que se está discutiendo es el alcance de la competencia de las Comunidades Autónomas en materia de Función Pública; es decir, la interpretación del famoso 149, 1, 18. Esta aclaración previa le da base al Tribunal para reiterar, de entrada, la diferencia que existe entre el derecho de sindicación y la representación colectiva.

El razonamiento de la sentencia explica (3) que existe conexión entre ambos (a este propósito recuerda la sentencia que en nuestro sistema la representatividad sindical se mide por el criterio de la audiencia de las candidaturas sindicales en las elecciones a órganos de representación); pero hay que tener en cuenta, según la misma, que: 1) ha de distinguirse, con la Constitución y con la propia doctrina constitucional, entre derecho de sindicación y derecho de representación colectiva o de participación en la determinación de las condiciones de trabajo; 2) la regulación del derecho de sindicación viene atribuida exclusivamente al Estado $(28,1$, y 81,1$)$; y 3) la regulación de los órganos de representación de los funcionarios en las Administraciones Públicas «no constituye desarrollo legislativo de la libertad sindical y no puede incardinarse en la materia derecho de sindicación".

La siguiente afirmación de la sentencia (3), a saber, que la participación de los funcionarios en la fijación de sus condiciones de trabajo a través de los órganos de representación se integra en el régimen estatutario de los mismos, ha de tratarse sistemáticamente en el siguiente apartado. 
RÉGIMEN ESTATUTARIO DE LOS FUNCIONARIOS Y DERECHO DE PARTICIPACIÓN

En relación con la anterior afirmación del Tribunal Constitucional las tesis de los contendientes en el conflicto de competencia son, naturalmente, encontradas.

Para el Gobierno de la Nación, el derecho de representación colectiva de los funcionarios forma parte de las bases en materia de condiciones de empleo de los funcionarios públicos, y la falta de regulación estatal en esta materia no puede colmarse acudiendo a la normativa preconstitucional (4). Mientras que, para el Consejo de Cantabria (5), sí existen normas estatales reguladoras de tal materia (citando al respecto el artículo 5. del Real Decreto 1522/1977 y la Resolución de la Dirección General de Administración Local de 29 de enero de 1981), añadiendo, además, que el Decreto cuestionado no interfiere en la libertad sindical ni afecta al régimen estatutario de los funcionarios públicos (6).

Para el Tribunal Constitucional (6) la representación colectiva o la participación "supone la regulación sustantiva de un derecho estatutario de los funcionarios", y, más concretamente, esta regulación ha de incardinarse dentro del régimen estatutario de los mismos. Lo que no hace, claramente, el Tribunal Constitucional es calificar de básica esta materia, porque, como luego veremos, lo que no se reconoce a la Comunidad Autónoma de Cantabria, dado su nivel autonómico al haber accedido a la autonomía por la vía del artículo 143, es la competencia legislativa de desarrollo prevista en el artículo 149, 1, 18.

En este punto es conveniente recordar el texto de la Disposición final del Proyecto de Ley de Organos de representación, ya citado, cuando dice que las normas de la presente Ley se considerarán bases del régimen estatutario de los funcionarios públicos, dictadas al amparo del artículo 149, 1, 18, de la Constitución.

FunCión Pública: oRganización de la buRocracia Y REGULACIÓN DE LA RELACIÓN DE SERVICIO

Dentro de la Función Pública conviene, según la sentencia (6), distinguir un doble aspecto: la organización de la burocracia y la regulación de la relación de servicio. 
La organización de la burocracia, como materia organizativa que es, lleva al Tribunal a plantearse la cuestión del alcance de la potestad de autoorganización. Las afirmaciones de la sentencia a este respecto son importantes.

En primer lugar, se establece que la competencia autonómica en materia de organización de las instituciones de autogobierno no puede tener otro alcance mayor que el que deriva de la Constitución y del Estatuto; es decir, tal competencia ha de entenderse referida a la organización de la Asamblea Regional, el Consejo de Gobierno y la Presidencia; si bien, añade, «aun cuando las instituciones de autogobierno sean primordialmente las que el Estado crea y la Constitución garantiza, la Comunidad Autónoma puede crear otras en la medida en que lo juzgue necesario para su autogobierno".

Hay que señalar en este extremo que la doctrina constitucional sobre el sentido de la expresión instituciones de autogobierno, según la cual, en la competencia autonómica reconocida ex constitutione para regular las mismas, no se comprende la potestad de crear y organizar la propia estructura administrativa autonómica, ha merecido algunos reparos por parte de algún sector de estudiosos del Derecho de Autonomías (Parejo Alfonso y MuÑoz Machado).

En segundo lugar, precisa la sentencia (6), la potestad de autoorganización no puede extenderse hasta abarcar, además de la organización de la respectiva Administración Pública, el régimen estatutario de sus funciones. O sea, aunque el Estatuto de Cantabria -artículo 35- atribuya a la Comunidad Autónoma la creación y estructuración de su propia Administración Pública, dentro de los principios generales y normas básicas del Estado, de ello no cabe deducir que la Comunidad tenga competencia para regular la relación de servicio y el régimen estatutario de sus funcionarios. Bien es verdad que la sentencia reconoce que sí puede la Comunidad Autónoma de Cantabria "conformar libremente la estructura orgánica de su aparato administrativo e incluso dictar normas que afecten a la relación orgánica que liga a los funcionarios públicos con el citado aparato, con las consiguientes potestades de dirección o jerarquía».

En tercer lugar, reconoce el Tribunal una cierta vinculación entre la materia organizativa y la regulación de la relación de servicios y régimen estatutario, "pues aun cuando esta materia esté vinculada a la estructura de la Administración autonómica, posee una naturaleza claramente diferenciable de las cuestiones estricta- 
mente organizativas». Más adelante, reiterando la recíproca incidencia de ambas regulaciones, la sentencia (7) afirma que las normas estatales sobre el régimen estatutario de los funcionarios «pueden desconocer las características propias de la organización administrativa autonómica y, por lo tanto, no adaptarse con la suficiente eficacia y precisión a ellas». Añadiendo que, en este sentido, no puede olvidarse la relativa incidencia que la diversidad de regímenes organizativos de las Administraciones Públicas tiene sobre las relaciones de éstas con el personal a su servicio.

La doctrina constitucional que acabamos de resumir en los apartados anteriores tiene cabal reflejo en el Proyecto de Ley de Organos de representación, reiteradamente citado, y cumple aquí subrayarlo, por lo que un eventual achaque de inconstitucionalidad del referido Proyecto en este punto estaría condenado al fracaso. En efecto, el artículo 34, 1, del Proyecto de Ley excluye, entre otras, de materia de consulta o negociación a «las decisiones de las Administraciones Públicas que afecten a sus potestades de organización» (con lo que se recoge la diferenciación entre materia organizativa y materia de relación de servicio), y, además, el mismo Proyecto de Ley dispone -art. 34, 2- que cuando aquellas decisiones "puedan tener repercusión sobre las condiciones de trabajo de los funcionarios públicos procederá la consulta a las Organizaciones sindicales y Sindicatos" (con lo que se viene a reconocer la posible incidencia del campo organizativo en el de la relación funcionarial de servicio).

Competencias de una Comunidad Autónoma de la via del artículo 143 en materia de Función Pública

La tesis del Gobierno de la Nación —que finalmente resulta asumida por la sentencia- es, en este punto, que la Comunidad de Cantabria, al haber accedido a la autonomía por la vía del artículo 143, no puede ampliar sus competencias asumiendo las comprendidas en el artículo 149 de la Constitución y, por tanto, carece de la competencia legislativa de desarrollo prevista en el artículo 149, 1, 18; en consecuencia, sus competencias en materia de Función Pública no trascienden del plano ejecutivo (4).

La sentencia (6) concluye que ello "hace que no aparezca en su Estatuto, como ocurre en otras Comunidades de mayor nivel autonómico, un título específico en materia de Función Pública, deri- 
vado del artículo $149,1,18$, de la Norma fundamental». Sin embargo, sigue diciendo, ello no significa que la Comunidad carezca por completo de competencias en esta materia.

¿Cuáles? Pues las que antes hemos visto se derivan de la potestad de autoorganización en cuanto afecta a la Función Pública.

¿En qué consisten las facultades de la Comunidad Autónoma en materia de Función Pública? Según la sentencia (6), «sólo posee competencia de ejecución de la normativa estatal»; es decir, la de aplicar esa normativa estatal a los propios funcionarios de la Comunidad Autónoma. En las mismas palabras de la sentencia (6):

«Ante todo, tiene competencias de ejecución de las normas aprobadas por el Estado en lo que concierne al personal al servicio de la Administración autonómica, incluidos los funcionarios transferidos, dado que, como resulta expresamente de lo dispuesto en el artículo 25, 3, de la Ley del Proceso Autonómico, su relación orgánica y la funcional o de servicios se establecen con dicha Administración y no con la del Estado. A esos funcionarios y personal contratado le son aplicables, de acuerdo con la Disposición Transitoria novena, tres, del Estatuto de Cantabria, las disposiciones del Estado y demás Administraciones Públicas relativas a su régimen jurídico, y no cabe duda de que la aplicación de las mismas corresponde a la Comunidad Autónoma en la que sirven».

Pero como las competencias de ejecución, o aplicación, de las normas estatales llevan implícita, según el artículo 32, 3, del Estatuto cántabro, la correspondiente potestad reglamentaria para la organización interna de los servicios, y - sigue razonando la sentencia-como una aplicación de tales normas estatales (aplicación simplemente mecánica, en feliz expresión del Tribunal), podría desconocer las peculiaridades de la organización administrativa de la Comunidad, lo que sí podrá hacer esta Comunidad es adaptar de algún modo las normas estatales sustantivas del régimen de los funcionarios (en este caso, las relativas al ejercicio del derecho de representación) a las peculiaridades de su propia organización. Consideramos oportuno reproducir literalmente este pasaje de la sentencia (7) por su doctrina sobre el régimen de los funcionarios, que deja a salvo, en todo caso, la potestad de autoorganización:

"De ello se deduce que la Comunidad Autónoma, si bien no puede en ningún caso modificar o desarrollar las normas del Estado sobre el régimen estatutario de los funcionarios públicos en lo que atañe al régimen sustantivo de las relaciones jurídicas funcionaria- 
les, sí puede en cambio utilizar instrumentos normativos propios para hacer posible el ejercicio de los derechos y obligaciones, deberes y facultades $y$, en general, de las situaciones jurídicas que aquel régimen sustantivo contempla, dentro de la estructura organizativa de su Administración. De otro modo, en efecto, podría suceder que la ejecución de la normativa estatal sólo pudiera llevarse a cabo con el sacrificio de la propia competencia de autoorganización».

Finalmente, aplicando la doctrina que acabamos de transcribir al supuesto concreto del conflicto, la sentencia concluye (8):

«La Diputación Regional puede, en consecuencia, en cuanto que Comunidad Autónoma uniprovincial, aplicar dicha Resolución (la de 29 de enero de 1981, citada) teniendo en cuenta sus peculiaridades organizativas mediante la correspondiente reglamentación interna, respetando el régimen sustantivo del derecho de representación colectiva establecido por el Estado».

En resumen, la doctrina esencial establecida por la sentencia puede condensarse en las siguientes proposiciones:

- El derecho de sindicación y el de representación colectiva, pese a su conexión, son distintos y no puede considerarse el segundo un aspecto esencial del primero.

- En materia de Función Pública hay que destacar un doble aspecto: la organización de la burocracia de las Administraciones Públicas y la regulación de la relación de servicio, contenido indiscutible esta última del régimen estatutario de los funcionarios.

- La representación colectiva o la participación de los funcionarios en la determinación de sus condiciones de trabajo supone la regulación sustantiva de un derecho estatutario de los mismos.

- La potestad de autoorganización de las Administraciones Públicas no puede extenderse hasta abarcar, además de la organización de la respectiva Administración, el régimen estatu. tario de los funcionarios.

- La relación de servicio y el régimen estatutario de los funcionarios poseen una naturaleza claramente diferenciable de las cuestiones organizativas, si bien el régimen organizativo tiene una relativa incidencia sobre las relaciones de las Administraciones Públicas con el personal a su servicio. 
- Las normas estatales que regulan el ejercicio del derecho de representación colectiva de los funcionarios pueden ser aplicadas por las Comunidades Autónomas, adaptándolas a las. características de su específica organización administrativa, sin alterar el régimen sustantivo de aquel derecho, lo cual no supone invasión de las competencias estatales en materia de régimen estatutario de los funcionarios. 
REALA-1986, núm. 232. DIEZ RONCAL, ANGEL. EL DERECHO DE REPRESENTACION COLECTIVA...

REALA-1986, núm. 232. DIEZ RONCAL, ANGEL. EL DERECHO DE REPRESENTACION COLECTIVA... 